\title{
PANORAMA DO DIREITO DA PROPRIEDADE INDUSTRIAL NA AMÉRICA LATINA ${ }^{(*)}$
}

\author{
PANORAMA OF THE INDUSTRIAL PROPERTY RIGHT IN LATIN AMERICA
}

\author{
Dirceu Yoshikazu Teruya ${ }^{(* *)}$ \\ Instituto Nacional da Propriedade Industrial, Rio de Janeiro (RJ), Brasil
}

Resumo: O conhecimento tem sido relevante para a sociedade dos países, quer seja para realização de negócios, quer seja para proteção. A propriedade industrial é um instrumento de modelos de negócios. Esse instrumento tem sido amplamente discutido na esfera internacional desde a Rodada Uruguai do Acordo Geral de Tarifas e Comércio (GATT). A América Latina tem um uso limitado do Sistema de Propriedade Industrial em face de suas características econômicas e institucionais e tem uma participação relativa de não residente nas patentes concedidas nos países latino-americanos.

Palavras-chaves: Direito de Propriedade Industrial; América Latina; Apropriabilidade.

Abstract: Knowledge has been relevant to the society of the countries for encouraging business and protection of knowledge. The industrial property rights are an instrument of business models. This instrument has been discussed extensively in the international arena since the Uruguay Round of General Agreement of Trade and Tariffs (GATT). Latin America has been a limited use of the Industrial Property System due to their economic and institutional features and has a relative share of non-resident patents granted in the Latin American countries.

Keywords: industrial property rights; Latin America; appropriability.

(*) A discussão apresentada nesse capítulo não necessariamente converge com as ideias defendidas pelo Instituto Nacional da Propriedade Industrial. Os erros e omissões são de responsabilidade do autor.

(**) Doutor, Pesquisador em Propriedade Industrial do Instituto Nacional da Propriedade Industrial. E-mail:<teruya@inpi. gov.br>. Recebido em: 08.08.2014, aceito em: 10.11.2015. 


\section{INTRODUÇÃO}

A criação de conhecimento é fruto de ação coletiva e de diferentes agentes públicos e privados envolvidos nas diferentes etapas, quer seja financiando o desenvolvimento do conhecimento, transação e o uso do conhecimento, quer seja na geração de bens e serviços disponibilizados ao mercado de bens e serviços.

O direito de propriedade intelectual é um instrumento de proteção e difusão do conhecimento utilizado pelos agentes do processo, conforme o desenho do modelo de negócio dos agentes econômicos. Esse instrumento apresenta uma abrangência de proteção e um aparato regulatório definido pelos Estados Nacionais.

A América Latina tem construído, ao longo do tempo, uma estrutura de Ciência e Tecnologia ( $C \& \mathrm{~T}$ ) tais como institutos de pesquisas e universidades, que apresentam uma produção de conhecimento, mas esses agentes produtores de conhecimento localizados nos países da América Latina têm uma participação relativamente pequena nos conhecimentos formalizados, como é o caso da propriedade intelectual. Em relação à Pesquisa e Desenvolvimento ( $\mathrm{P} \& \mathrm{D}$ ), observa-se que ainda está em processo de estruturação por parte das empresas nacionais, sendo que o papel das subsidiárias instaladas na América Latina já está definido que, na sua maioria, somente realiza a produção e adaptação do produto e do processo às realidades locais.

Além disso, os países da América Latina apresentam limitações na capacidade de produção e a integração da produção do conhecimento com à geração de riqueza e do uso do sistema de propriedade intelectual como instrumento de apropriabilidade.

Do ponto de vista da metodologia, optamos pela revisão da literatura relacionada ao papel da propriedade intelectual. Na sequência, são apresentados os dados referentes à participação da propriedade industrial entre residentes e não residentes concedidas pelos países da América Latina como proporção mundial e da participação de patentes concedidas aos agentes dos países da América Latina nos Estados Unidos, dada a importância econômica deste país.

A estrutura do trabalho é a seguinte: primeiramente, far-se-á uma revisão da literatura sobre o escopo da propriedade intelectual, com ênfase na propriedade industrial. Na segunda parte, apresentar-se-á contexto econômico e da geração do conhecimento na América Latina. Na terceira parte, serão discutidos a situação e o perfil da propriedade industrial na América Latina.

\section{ASPECTOS DA PROPRIEDADE INTELECTUAL: UMA BREVE REVISÃO DA LITERATURA}

O conhecimento tem sido importante para as organizações na geração de soluções aos problemas de produtos e processos científicos e tecnológicos. A geração do conhecimento pode servir como suporte à atividade de criação e soluções tanto no processo quanto no produto. 
O conhecimento pode ser classificado em (LUNDVALL, 1992):

I. conhecimento tácito: o conhecimento tácito é aquele não codificado ou armazenado na forma de segredo de negócios ou industrial tais como o know-how e a diferença do background tecnológico entre diferentes agentes em um meio competitivo. Esse tipo de conhecimento é baseado nas habilidades acumuladas ao longo do tempo tanto pelas organizações como pelos indivíduos e apresenta dificuldades no processo de difusão;

II. conhecimento explícito: o conhecimento explícito é aquele codificado na forma de livro, manual, patente e contidas em outras plataformas, tais como a virtual, com acesso disponível ao público em geral.

A geração do conhecimento tem sido relevante à sociedade na geração de bens e serviços demandados. Segundo Stiglitz (1999) e Dosi (1988), o conhecimento é caracterizado por ser um bem público, segundo os seguintes princípios:

I. a não rivalidade: o custo marginal do acesso ao conhecimento é zero por um consumidor adicional para qualquer nível de produção;

II. a não exclusividade: o conhecimento é indissociável, por isso, os indivíduos não podem ser excluídos do consumo.

Uma parte do conhecimento gerado é estruturado na forma de segredo industrial, que confere ao agente uma vantagem competitiva aos demais agentes econômicos. Para tanto, é necessária uma governança da proteção dessa forma de conhecimento para que não haja a disseminação do conhecimento para os demais agentes. Assim, as cláusulas contratuais relacionadas à confidencialidade com os colaboradores são importantes para que as empresas mantenham o tempo de liderança sobre os competidores (lead time).

Outra parte do conhecimento produzido encontra-se na forma de direito de propriedade intelectual como instrumento de proteção e difusão do conhecimento e instrumento de modelo de negócio. O direito de propriedade intelectual refere-se ao direito relativo à geração de um conhecimento, que é uma forma de evitar que terceiros explorem sem permissão do titular do direito.

O direito de propriedade intelectual é dividido em (WIPO, 2004):

I. direito de autor: o direito de autor representa criações do espírito humano disponibilizado em uma determinada plataforma física e/ou virtual. O direito autoral abrange composições musicais, programas de computador, livros, artigos científicos;

II. direito de propriedade industrial: essa parte do direito de propriedade industrial está relacionada com a atividade industrial e a diminuição da assimetria da informação para os demais agentes. Fazem parte do direito de propriedade industrial: patente, desenho industrial,marca e indicação geográfica.

III. direitos "sui generis": são direitos não relacionados ao direito autoral e ao direito de propriedade industrial. É um conjunto de direitos, que abrange topografia de circuito integrado, novas variedades vegetais, conhecimentos tradicionais e folclore.

A propriedade intelectual apresenta as seguintes características (TERUYA, 2010):

I. territorialidade: os titulares dos direitos de propriedade industrial requerem esses direitos de propriedade industrial nos países que os titulares tenham interesse. Outro 
aspecto da territorialidade esta relacionado com a regulamentação do escopo de direito de propriedade industrial dos países, cada país apresenta uma autonomia relativa na regulação dos direitos de propriedade intelectual. Apesar de terem acordos internacionais que homogeneízam o grau mínimo de direito de propriedade intelectual, o grau máximo de proteção dos direitos de propriedade industrial está de acordo com a estratégia dos Estados nacionais, segundo suas trajetórias de desenvolvimento;

II. espectro temporal: os direitos de propriedade intelectual apresentam uma dimensão temporal, ou seja, durante um determinado período de tempo, o titular desse direito pode explorar exclusivamente o direito concedido e auferir retorno econômico. Depois da vigência do direito de propriedade intelectual, terceiros podem utilizar o direito sem a autorização do titular;

III. abrangência do direito: o direito de propriedade intelectual apresenta uma abrangência de proteção deliberada por um marco regulatório do Estado Nacional;

IV. segurança jurídica: o direito de propriedade intelectual é um instrumento concedido e normalizado pelo Estado aos agentes econômicos para que possam ter a segurança jurídica de utilizar o instrumento para geração de valor econômico;

V. revelação do conteúdo protegido: Ao submeter o pedido de registro direito de propriedade intelectual, os agentes necessitam revelar o conteúdo a ser protegido para que outros agentes possam ter a informação do que não solicitar por esse mecanismo de proteção.

O uso do Sistema de Propriedade Intelectual pelos agentes implica aos agentes no custo da manutenção do direito concedido, a fim de evitar uso de má-fé pelos agentes (ANDERSEN; KONZELMANN, 2008). Além disso, as regras do jogo são importantes para a tomada de decisão dos agentes:

I. os agentes necessitam atender aos requisitos do escopo do direito de propriedade intelectual e de solicitação dos direitos de propriedade intelectual aos organismos responsáveis pela concessão desses direitos em cada país;

II. o uso do sistema de propriedade intelectual apresenta custo da geração do conteúdo, custo de pagamento das retribuições para manter os direitos vigentes e o custo de monitoramento contra uso indevido de terceiros;

III. o uso do sistema de propriedade intelectual possibilita aos agentes o cerceamento do conhecimento, principalmente para os setores baseados em conhecimento;

IV. o uso do sistema de propriedade intelectual pode minimizar custos de transação envolvendo ativos intangíveis entre os agentes como o licenciamento de direito de propriedade intelectual, valoração e venda de ativos intangíveis.

A conformidade do sistema de propriedade Intelectual é um instrumento na tomada de decisão dos agentes econômicos para a apropriabilidade, uma vez que os agentes econômicos buscam uma taxa de lucratividade dos investimentos realizados (TEECE, 1986).

I. regime de apropriabilidade: o regime de apropriabilidade esta associado com a natureza da tecnologia e a eficácia do marco regulatório para a apropriabilidade dos lucros. A 
natureza da tecnologia está relacionada à combinação de conhecimentos tácitos e explícitos no desenvolvimento de uma determinada solução. Um outro aspecto desse regime está relacionado com o aspecto institucional, como Direito de Propriedade Intelectual, que dá suporte às tomadas de decisões dos agentes econômicos;

II. desenho do paradigma dominante: o paradigma tecnológico é a capacidade de oferecer soluções a problemas técnicos. Para um determinado paradigma ser dominante, existe uma disputa entre os paradigmas na fase pré-paradigmática, vai ser ganhador o paradigma tecnológico que for mais eficaz na solução dos problemas. No momento que o paradigma vigente não consegue dar mais resposta aos problemas técnicos e econômicos, emerge um novo paradigma;

III. ativos complementares: o desenvolvimento e a inserção de produtos e serviços inovadores têm a necessidade de instrumentos como acordo de cooperação técnica, certificação, logística, canais de distribuição, assistência técnica e marketing a fim de que o produto ou serviço efetivamente chegue ao consumidor final ou intermediário. Segundo Teece (1986), existem diferentes tipos de ativos complementares: (i) ativos genéricos - aqueles encontrados com menos barreiras no mercado para atender às necessidades das atividades das empresas; (ii) ativos especializados - aqueles que dependem da competência de um determinado quer seja interno ou externo ao agente econômico; (iii) ativos coespecializados - os que dependem de um processo de cooperação com outros agentes para desenvolver uma determina rotina ou solução para o agente.

Também o uso do instrumento de propriedade intelectual está relacionado à dinâmica setorial e ao processo inovativo de cada setor. Isso se deve ao fato de que os setores industriais apresentam configuração diferente no uso e na função do mecanismo da propriedade intelectual nas duas atividades de P \& D, de processo e de produto..

Cabe destacar que a propriedade intelectual não apresenta uma correlação com a taxa de inovação, pois o processo de inovação depende de outros instrumentos tais como a regulação, ambiente de investimento em Pesquisa e Desenvolvimento (P \& D) e produtivo e das variáveis macroeconômicas. Existem exceções apontadas na literatura, como o setor farmacêutico e outros setores intensivos em conhecimento, uma vez que o direito de propriedade intelectual tem uma importância relativa no processo de apropriabilidade. Ao mesmo tempo, a patente é um dos resultados do investimento em Pesquisa e Desenvolvimento dos agentes econômicos (DOSI et al., 2006).

Na próxima seção, será abordado o uso dos instrumentos de propriedade industrial na América Latina.

\section{CONTEXTO DA AMÉRICA LATINA E A PROPRIEDADE INTELECTUAL NOS ANOS 1990 E 2000}

O desenvolvimento do conhecimento dos países da América Latina apresenta uma produção de conhecimento relacionado ao investimento em Ciência e Tecnologia (C \& T) e Pesquisa e Desenvolvimento (P \& D). No entanto, os resultados não são expressivos 
em relação ao cenário internacional. Isso se deve ao fato de que os agentes do Sistema de Inovação dos países latino-americanos não são articulados o suficiente para promover um efeito transbordamento no sistema de inovação no médio e longo prazos (BRISOLLA; ETZKOWITZ, 1999).

Em termos de investimento em $C \& \mathrm{~T}$, como se pode observar no gráfico 01, tem-se uma tendência positiva em termos de dispêndio em $C \&$ T e P \& D entre 2000 e 2010 (calculado em volume de PIB). O dispêndio de C \& T saiu de uma base ao redor de 0,7\% para $1,1 \%$ do PIB, já os dispêndios de P \& D saíram de uma base ao redor de 0,5\% para 0,8\% do PIB. No entanto, em uma análise por período, observa-se uma redução entre 1997 e 2001 dos dispêndios em C \& T e P \& D, por conta da necessidade dos ajustes necessários dos governos latino-americanos na segunda metade dos anos 1990.

Cabe destacar que a configuração do perfil dos agentes econômicos e não econômicos nos países latino-americanos é heterogêneo. Têm-se países líderes em ciência e tecnologia como Argentina, Brasil e México decorrentes de investimento majoritariamente público ao longo de décadas; um conjunto de países intermediários como Colômbia, Venezuela, Chile, um conjunto de países pequenos com pouco dispêndio em $C$ \& T e P \& D como Honduras, El Salvador, Bolívia, Panamá por conta de restrição de estrutura de $C \& \mathrm{~T}$ e de investimento pelos empresários locais em $\mathrm{P} \& \mathrm{D}$.

O financiamento das atividades de P \& D e C \& T nos países da América Latina tem sido majoritariamente público por conta do risco e da incerteza no processo inovativo e por conta que as organizações de $C \&$ T serem preponderamente públicos nesses países. Além disso, os governos da maioria dos países latino-americanos montaram empresas estatais responsáveis por uma parte significativa do investimento em $\mathrm{P} \& \mathrm{D}$ do setor empresarial até os anos 1990, quando uma grande parte delas foi privatizada.

Como resultado do investimento em C \& T, quer seja público e privado na América Latina, tem-se um aumento da publicação indexada dos pesquisadores latino-americanos nas bases Thompson e Scopus, conforme a tabela 1. Segundo a base Thompson, a participação de 2,31\%, em 1996, para 4,31\%, em 2009, já, na base Scopus, a participação da comunidade científica latino-americana saiu de 2,07\%, em 1996, para 4,47\% de artigos produzidos pela comunidade científica no mundo em períodicos indexados.

Existem esforços da comunidade científica latino-americana na produção de pesquisa científica e tecnológica associada com ações de políticas públicas, mas ainda não apresenta os requisitos suficientes de ser uma referência internacional em muitas áreas do conhecimento.

Cabe destacar, segundo os dados de SCImago (2007), que uma parte considerável das publicações da América Latina tem sido realizada no Brasil, fruto de programas e ações de C \& T desde os anos 1950 com a constituição da Coordenação de Aperfeiçoamento de Pessoal de Nivel Superior (CAPES) e do Conselho Nacional de Desenvolvimento Científico e Tecnológico ( $\mathrm{CNPq})$, que tem coordenado a parte de fomento à pesquisa científica e tecnológica. Além disso, grande parte da publicação realizada na América Latina no período de 2000 e 2010 está concentrada em poucos países latino-americanos, o que demonstra que existe uma configuração diferenciada entre os demais países latino-americanos. 
O ambiente institucional na América Latina também tem sido um fator importante na tomada de decisão de investimento Pesquisa e Desenvolvimento (P \& D) nos anos 2000. Mesmo com a abertura comercial nos anos 1990, estabilização econômica e a privatização de empresas estatais, ainda tem-se a restrição do investimento em $\mathrm{P} \& \mathrm{D}$ pelas firmas. Sabe-se que as mudanças estruturais não têm ocorrido na velocidade desejada para reverter as expectativas de investimento no curto prazo. Essas mudanças estruturais são decorrentes de convenções sociais e econômicas que, no caso latino-americano, ocorrem em uma velocidade relativamente menor do que a necessária, dado o esforço da construção dos consensos pelos representantes da sociedade (ERBER, 2002).

O Sistema de Propriedade Intelectual foi organizado no final do século XIX por uma série de acordos internacionais para atenuar o custo de transação relativo ao uso do Sistema de Propriedade Intelectual em diferentes países, em razão da sua estratégia de internacionalização e de proteção do conhecimento (MACHLUP; PENROSE, 1950).

A América Latina tem usufruído do Sistema de Propriedade Intelectual ao longo das últimas décadas ainda de forma restrita. Mesmo com os acordos internacionais assinados entre os membros do Acordo Geral de Tarifas e Comércio (GATT), posteriormente, Organização Mundial do Comércio (OMC), os agentes dos países latino-americanos ainda têm pouco destaque. Durante as negociações da Rodada Uruguai no âmbito do GATT, no período de 1986-1994, o tema do direito de propriedade intelectual entrou na pauta de negociações do comércio internacional. Como resultado das negociações dessa rodada, os países latino-americanos e outros participantes da negociação firmaram o Acordo de Marrackesh em 1994 com um anexo dedicado à propriedade intelectual, denominado Aspectos dos Direitos de Propriedade Intelectual Relacionados ao Comércio (TRIPs) (DIAZ, 2008).

A partir desse acordo, a estrutura do Sistema de Propriedade Intelectual dos países latino-americanos signatários do Acordo de Marrackesh apresentou uma alteração com uma uniformização do escopo do direito de propriedade intelectual. Os países latino-americanos tiveram que modificar seus marcos regulatórios, que ampliaram a abrangência do direito de propriedade intelectual concedido em seus países. Esse novo contexto tem restringido a adoção de ações de políticas públicas nacionais, a partir do direito de propriedade intelectual para definir sua estratégia de desenvolvimento nacional.

Ao mesmo tempo, como se tem uma dificuldade de negociar os termos desse Acordo, por envolver um conjunto de países, os países têm buscado negociações bilaterais de comércio, principalmente com os Estados Unidos para terem o acesso ao mercado americano de bens e serviços. A implicação desses acordos é o aumento da abrangência de proteção dos direitos de propriedade intelectual em relação ao TRIPs, o que implica no aumento dos níveis de proteção dos direitos de propriedade intelectual. A negociação de acordos bilaterais sob a perspectiva dos países latino-americanos ainda está concentrada no comércio internacional (DIAZ, 2008; MIRANDA, 2011).

Entretanto, as ações efetivas para utilizar o Sistema de Propriedade Intelectual pelos países latino-americanos de forma a beneficiar os agentes econômicos para uma efetiva apropriação ainda é restrita (LÓPEZ, 2008). 
Os diferentes agentes do Sistema de Inovação nos países latino-americanos ainda têm dificuldade de utilizar o mecanismo do direito de propriedade intelectual como mecanismo de promover negócios, mapeamento tecnológico e transferência de tecnologia entre empresa e empresa e entre universidade e empresa. A importação de tecnologia e o licenciamento de direito de propriedade industrial tem sido instrumentos utilizados para capacitação tecnológica dos agentes localizados nos países latino-americanos.

Na próxima seção, será apresentado o quadro do uso do sistema de propriedade industrial pelos agentes latino-americanos e sua representatividade no cenário internacional.

\section{PERFIL DO USO DO DIREITO DE PROPRIEDADE INDUSTRIAL NA AMÉRICA LATINA NOS ANOS 1990 A 2010}

O uso do Sistema de Propriedade Industrial na América Latina apresenta uma proporção reduzida se comparado com a dos países em desenvolvimento. O Sistema de Propriedade Industrial não é somente para a proteção dos direitos para barreiras à entrada, mas também um mecanismo de negociação.

A adoção dos instrumentos de propriedade industrial pelos agentes latino-americanos tem sido diferente para cada direito, pois cada direito de propriedade industrial apresenta uma especificidade diferente e cada setor produtivo e de serviço utiliza o sistema de propriedade intelectual de forma diferenciada de apropriabilidade.

Dessa forma, os agentes econômicos utilizam o Sistema de Propriedade Intelectual e protegem o conhecimento gerado tanto nos países de origem quanto em outros países considerados estratégicos. Por isso, existem direitos de propriedade intelectual concedidos a não residentes nos países latino-americanos a fim de esses agentes explorarem economicamente esses direitos.

A patente é um instrumento relacionado com o progresso técnico. Uma parte dos inventos derivados do investimento em $\mathrm{P} \& \mathrm{D}$ é patenteado. O critério de patentiabilidade está relacionado com o princípio da novidade, atividade inventiva, aplicação industrial e relatório descritivo. Além disso, os critérios de patentiabilidade podem ser mais amplos em relação aos parâmetros deliberados no Acordo TRIPs por conta de acordos bilaterais e/ou de acordo com a estratégia de desenvolvimento do país.

Conforme os gráficos 02 e 03, verifica-se uma taxa de crescimento das patentes concedidas a residentes e não residentes no mundo, a partir de 1990, principalmente pelos países desenvolvidos. Em contrapartida, nos países latino-americanos, têm-se uma oscilação da quantidade das patentes de não residentes e uma leve tendência de queda no número de das patentes concedidas por residentes na América Latina.

A trajetória de patentes concedidas por não residentes foi crescente, a partir de 1994, com a adesão dos países latino-americanos ao Acordo de Marrackesh, pois aumentou a abrangência do direito patentário, ou seja, incluíram-se campos tecnológicos que não eram passíveis de patenteamento nos países latino-americanos. Além disso, o resultado do investimento em $\mathrm{P} \& \mathrm{D}$ pelos agentes de outros países e a estratégia de internacionalização da produção e comercialização de bens têm contribuído com o aumento da concessão de carta patente nos países latino-americanos pelos não residentes (DIAZ, 2008). 
Cabe destacar que as patentes concedidas não necessariamente são utilizadas no processo inovativo (DOSI, et al., 2006). Isso se deve ao fato de que o processo inovativo utiliza parte de conhecimento tácito e parte do conhecimento explícito, sendo que as proporções dependem do modelo de negócio das empresas.

Nos gráficos 04 e 05, observa-se uma participação relativamente acima de 80\% das patentes concedidas na América Latina a titulares não residentes e uma redução ao redor de 20\% de residentes, em 1980, para menos de 10\%, em 2012. No mundo, existe uma tendência de serem concedidas patentes majoritariamente a residentes, muito por conta dos países da Tríade (União Europeia, Japão e Estados Unidos) e a China como países de elevados investimento produtivo e em P \& D.

Já a situação dos residentes na América Latina apresenta uma situação de trajetória descendente da taxa de crescimento de patentes concedidas no período de 1995 a 2012. Essa situação se explica pelos níveis restritos de investimentos em P \& D e pela participação limitada na cadeia produtiva de valor dos agentes localizados na América Latina. O esforço inovativo dos agentes dos países latino-americanos ainda é bem restrito e o existente está concentrado nos agentes localizados na Argentina, Brasil e México. Além disso, a estrutura produtiva dos países latino-americanos está concentrada em commodities e nos setores de média e baixa intensidade tecnológica.

O modelo de utilidade é um direito de propriedade industrial relacionado ao progresso técnico, e está atrelada à agregação de funcionalidade e de aperfeiçoamento do estado da técnica, mas incorpora o princípio da atividade industrial, a utilidade e a novidade.

Observa-se nos gráficos 06 e 07 uma participação relativa significativa de modelos de utilidade concedido de residentes tanto na América Latina como no mundo de 1980 a 2012. Dessa tendência surge que o modelo de utilidade é realizado em países em desenvolvimento por conta da complexidade do desenvolvimento tecnológico, por isso, se concentram em realizar aprimoramentos de funcionalidades nos produtos. Além disso, países como Estados Unidos não apresentam o modelo de utilidade como direito de propriedade industrial, pois entendem que está inserida no escopo patentário.

Diante disso, existe uma parcela pouco expressiva de modelo de utilidade concedido a residente e uma parcela reduzida de não residentes com modelo de utilidade concedido na América Latina.

Nesse sentido, existe no mundo, uma participação altamente significativa de modelo de utilidade concedida a residente acima de $90 \%$ e uma participação abaixo de $10 \%$ de modelos de utilidades concedidos a não residente no período de 1980 a 2012, segundo o gráfico 08. Observa-se que a América Latina converge com a tendência mundial na concessão de modelo de utilidade, mas os países da América Latina apresentam uma proporção relativa maior à tendência mundial, com exceção no período de 1995 a 2000, em que o modelo de utilidade de não residente teve uma proporção considerável acima de $40 \%$ e, em 1996, maior que o modelo de utilidade concedido a residentes, conforme o gráfico 09.

O registro de desenho industrial é um instrumento de direito de propriedade industrial relacionado à forma plástica ornamental de um objeto ou conjunto ornamental de 
linhas e cores aplicado a um produto, proporcionando resultado visual novo e original na configuração externa e que sirva de tipo de fabricação industrial. Esse instrumento tem sido utilizado pelos agentes como diferenciação de produtos, principalmente nos setores eletroeletrônicos, automotivo e vestuário.

Em relação aos registros de desenho industrial concedidos, conforme o gráfico 10, destaca-se uma participação relativa considerável de registro de desenho industrial de residentes na América Latina em relação ao não residente de 1980 a 1994; posteriormente, esse quadro se altera com o aumento de registros concedidos a não residentes, a partir de 1995 por conta da importância relativa do mercado latino-americano pelos agentes de outros países e por conta da aprovação do Acordo de Marrackesh, que acentuaram a solicitação de registro de não residentes nos países latino-americanos. Apesar desse aumento de registro de não residentes, observa-se entre 2000 e 2012 uma oscilação nos registros concedidos dos não residentes, sendo que em 2004 e em 2011, o registro de residentes foi superior ao de não residentes em termos absolutos, mas nos demais anos o registro de não residentes foi superior ao de residentes na América Latina.

No mundo, existe uma maioria dos registros de desenho industrial de residente no período de 1980 a 2012, houve uma taxa de crescimento expressiva de registro de desenho industrial de residentes a partir de 1995, sendo que no registro de não residente houve um aumento em 1995 e 1997, mas, a partir daí, ficou praticamente estável os registros de não residentes no mundo, conforme o gráfico 11.

Em relação à participação do registro de desenho industrial entre residentes e não residentes, segundo o gráfico 12, verifica-se uma preponderância de registro de desenho industrial concedido a residentes no mundo. De 1980 a 1995, houve uma redução dos registros concedidos a residentes e um aumento de registros concedidos a não residentes, mas a partir de 1996 até 2012 há um aumento dos registros concedidos a residentes, chegando a quase $90 \%$ em 2012.

Na América Latina, conforme o gráfico 13, existe uma participação relativa maior de residente de 1980 a 1995, mas em uma tendência decrescente e oscilante e o movimento contrário dos não residentes. Por conta da implementação do Acordo de TRIPs, houve uma redução de participação de residente para nível de 20\% no período de 1996 a 2000 e um incremento para cerca de $50 \%$ da participação de registro de desenho industrial. Contudo, a participação de não residentes depois de 1996 tornou-se majoritária com exceção, em 2004 e 2010, de registros concedidos de desenho industrial na América Latina, conforme o gráfico 12.

A marca é um instrumento de propriedade industrial relacionado à distinguibilidade referente a bens e serviços. As marcas são palavras, sinais, signos, ou símbolos que identificam um produto e/ou serviço. Ela serve para diminuir a assimetria de informação e para promover a diferenciação entre os agentes que competem no mercado (RAMELLO, 2006).

Diferentemente das patentes concedidas, na maioria dos países latinos-americanos e no mundo, o registro de pedido de marcas é, na sua maioria, de titulares residentes, conforme o gráfico 14. Observa-se uma taxa de crescimento dos registros de marcas con- 
cedidos tanto para titulares residentes quanto para titulares não residentes de marcas na América Latina e no mundo.

No Gráfico 15, observa-se uma preponderância no cenário mundial de uma participação relativa maior de titulares residentes em relação aos titulares não residentes quanto ao registro de marca concedido. Cabe destacar que houve decréscimo da participação relativa dos registros de marcas concedidos para os titulares residentes no mundo e um aumento da participação relativa dos registros de marcas concedidos para os titulares não residentes no mundo no período de 1985 a 1995. Posteriormente, houve uma reversão de tendência com o aumento dos registros de marcas concedidos para não residentes e uma diminuição relativa dos registros de marcas concedidas para não residentes.

A América Latina acompanha a trajetória mundial de uma maior participação relativa de registros de marcas concedidos a titulares residentes em relação aos titulares não residentes, bem como o aumento do hiato entre a participação de registro de marcas concedidas de residentes e não residentes.

Essa situação verificada no mundo e na América Latina está relacionada com o raio dos negócios das firmas nos seus países, principalmente em serviços. Além disso, o aumento do número de registros de marcas reflete a necessidade de diminuição da assimetria de informações e promove a distinguibilidade entre os produtos e serviços disponibilizados pelos agentes econômicos.

Como o direito de propriedade industrial é territorial, ou seja, os titulares devem solicitar o pedido nos países que têm interesse em explorar economicamente o direito de propriedade industrial. Nesse sentido, os Estados Unidos são considerados o maior mercado consumidor do mundo de bens e serviços e esse país constitui uma oportunidade de negociação de tecnologia e de bens manufaturados por conta da dinâmica da economia americana. No gráfico 16, observa-se que existe uma quantidade pouco significativa de patentes concedidas nos Estados Unidos por residentes latino-americanos.

Uma parte da explicação desse número pouco significativo está vinculado com a restrição na geração e tecnologia capaz de gerar valor adicionado e ter um modelo de negócio, que utilize o instrumento patentário. Uma segunda explicação está relacionada com a restrição dos agentes latino-americanos na geração de tecnologia por conta de um departamento de P \& D desenvolvido e uma baixa internacionalização dos agentes latino-americanos na economia americana nos setores intensivos em conhecimento, como setor farmacêutico e setor aeroespacial.

Os líderes em patentes concedidas nos Estados Unidos têm sido Brasil e México decorrente de estratégias de internacionalização dos agentes conjugado com ações de ciência, tecnologia e inovação decorrente de políticas públicas. No entanto, a inserção de bens e serviços no mercado americano ainda tem uma pauta concentrada em produtos de baixo valor adicionado.

O uso do sistema de propriedade industrial tem aumentado no mundo e na América Latina nas últimas décadas. Entretanto, a taxa de crescimento mundial tem sido maior que a taxa de crescimento mundial em termos de patentes. Cada instrumento de propriedade industrial apresenta um escopo de proteção; diante disso, os agentes eco- 
nômicos utilizam o sistema de propriedade industrial, de acordo com suas estratégias de apropriação do conhecimento gerado.

\section{CONCLUSÃO}

Na América Latina, a produção de conhecimento pelos agentes econômicos tem avançado ao longo do século XX e persistindo essa tendência nas primeiras décadas do século XXI, fruto de investimento público e privado pelos agentes econômicos.

Um dos instrumentos possíveis de proteção e difusão do conhecimento é a propriedade intelectual, que tem sido utilizada pelos agentes econômicos depois da ratificação do Acordo de Marreckesh em 1994.

Os instrumentos de direito de propriedade intelectual tem sido usada de forma restrita pelos agentes da América Latina. Contudo, depois do Acordo de Marrackesh por meio do TRIPs e os acordos bilaterais com países latino-americanos, teve aumento da abrangência de proteção, o que reduziu a margem para os agentes nacionais latino-americanos a usarem o conhecimento protegido como forma de desenvolvimento tecnológico na região.

Nesse sentido, o direito patentário concedido nos países latino-americanos tem sido na sua maioria de não residentes por conta do resultado qualitativo e quantidade do investimento em $\mathrm{P} \& \mathrm{D}$ e da dinâmica dos agentes atuarem de forma internacionalizada.

Em contrapartida, os direitos de propriedade industrial, envolvendo marcas e desenho industrial, relacionados podem contribuir no processo de apropriabilidade. No caso de marcas, como instrumento de diminuição de assimetria da informação e de distinção ajuda no processo de fidelização do produto ou serviço perante o mercado consumidor nacional e na região latino-americana.

Cabe verificar, em estudos futuros a participação dos residentes latino-americanos, a posição na cadeia de valor e o uso do sistema de propriedade intelectual nas estratégias dos agentes econômicos. Além disso, examinar em que medida o aumento da abrangência de proteção dos direitos de propriedade intelectual afeta a estratégia dos agentes nos países latino-americanos, seguindo o setor produtivo e o tamanho das firmas.

Ao mesmo tempo, o processo de apropriabilidade pode não necessariamente estar relacionado com a patente, o que possibilita os agentes nos países latino-americanos a promoverem seu processo de inovação, aproveitando as janelas de oportunidades do mercado e coordenando melhor os investimentos em P \& D e canalizando esses resultados para maior efetividade dos produtos no mercado nacional e latino-americano.

\section{BIBLIOGRAFIA}

ANDERSEN, Birgitte; KONZELMANN, Sue. In search of a useful theory of the productive potential of intellectual property rights. Research Policy, v. 37, n. 01, pp. 12-28, 2008.

BRISOLLA, Sandra; ETZKOWITZ, Henry. Failure and success: the fate of industrial policy in Latin America and South East Asia. Research Policy, v. 28, pp. 337-350, 1999. 
DIAZ, Alvaro. América Latina y el Caribe: La propiedad intelectual después de los tratados de libre comercio. Santiago de Chile: Naciones Unidas, 2008.

DOSI, Giovanni. Technological paradigms and technological trajectories: a suggested interpretation of the determinants and directions of technical change, Research policy, v. 11, n. 03, pp. 147-162, 1982.

DOSI, Giovanni. Sources, Procedures, and Microeconomic Effects of Innovation. Journal of Economic Literature, v. 26, pp. 1120-1171, 1988.

DOSI, Giovanni; MARENGO, Luigi; PASQUALI, Corrado. How much should society fuel the greed of innovators? On the relations between appropriability, opportunities and rates of innovation, Research Policy, v. 35, n. 08, pp. 1110-1121, 2006.

ERBER, Fabio. Brazilian development in the nineties - myths, circles and structures, Nova Economia, v. 12, n. 01, p. 11-37, 2002.

FREEMAN, Christopher. Technology policy and economic performance-lessons from Japan. London: Frances Pinter, 1987.

LÓPEZ, Andrés. Innovation and Appropriability: Empirical Evidence and Research Agenda. In: WIPO. The Economics of Intellectual Property. Suggestions for Further. Research in Developing Countries and Countries with Economies in Transition, Ginebra: WIPO, 2009.

LUNDVALL, Bengt-Åke (Ed.). National System of Innovation: towards a theory of innovation and interactive learning. Londres: Pinter, 1992.

MACHLUP, Fritz; PENROSE, Edith. The patent controversy in the nineteenth century. The Journal of Economic History, v. 10, n. 01, pp. 1-29, 1950.

MIRANDA, Rafael Julio Pérez. Tratado de derecho de la propiedad industrial. Patentes, marcas, denominación de origen, obtentores de vegetales, informática. Un enfoque de derecho económico. Mexico: Editora Porrúa, 2011.

PAVITT, Keith. Sectoral patterns of technical change: Towards a taxonomy and a theory, Research Policy, v. 13, p. 343-373, 1984.

RAMELLO, Giovanni Battista. What's in a sign? trademark law and economic theory. Journal of Economic Surveys, v. 20, n. 04, pp. 547-565, 2006.

SCIMAGO JOURNAL \& COUNTRY RANK. National Science Indicators (NSI) da Thomson Reuters Scientific INC e SJR, 2007. Disponível em: <http://www.scimagojr.com> Acesso em: 16 jan. 2014.

STIGLITZ, J.Knowledge as a Global Public Good. In: I. GRUNBERG, K., I.; STERN, M. (eds.). Global Public Goods: International Cooperation in the $21^{\text {st }}$ Century, Oxford University Press, New York, pp. 308-325, 1999.

TEECE, David John. Profiting from technological innovation: implications for integration, collaboration, licensing and public policy. Research Policy, v. 15, pp. 285-305, 1986.

TERUYA, Dirceu Yoshikazu. Papel da propriedade intelectual na valoração de empresas inovadoras: oportunidades para micro, pequenas e médias empresas. Encontro Incubadora Tecnológica de Curitiba, Curitiba, 2010.

WORLD INTELLECTUAL PROPERTY ORGANIZATION INTELLECTUAL PROPERTY (WIPO). WIPOIntellectual Property Handbook: Policy, Law and Use, WIPO Publication, n. 487, Geneva. Disponível em: <http://www.wipo.int/about-ip/en/iprm/> Acesso em: 7 set. 2010. 


\section{APÊNDICES}

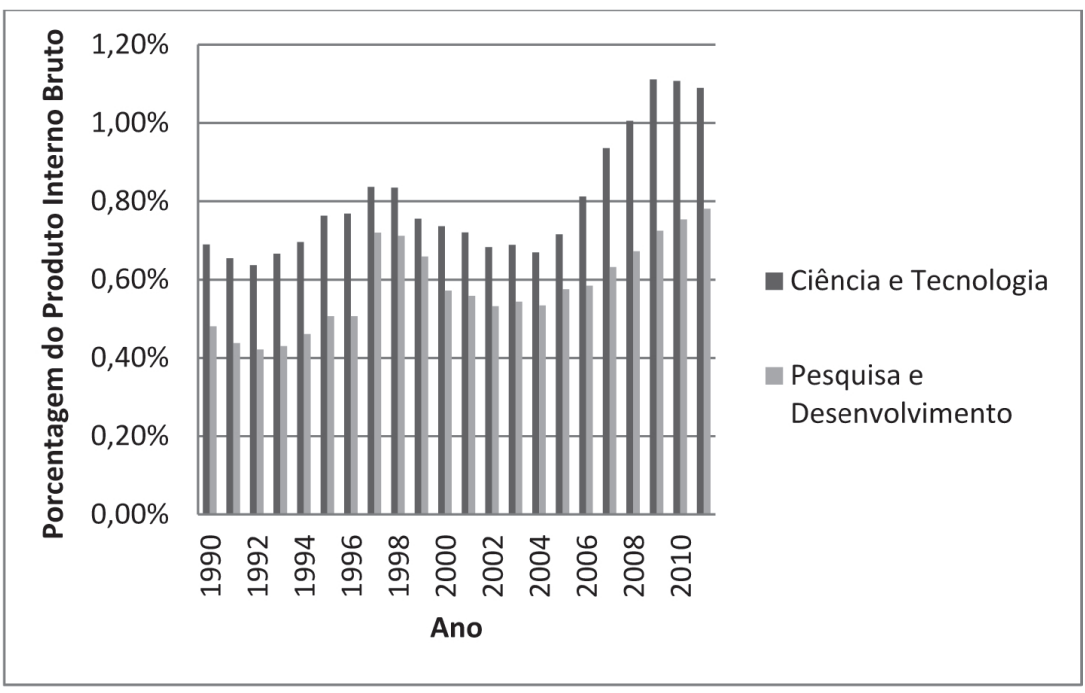

GrÁFICO 01

Participação no dispêndio em CiênCia e TeCnologia e Pesquisa e Desenvolvi-

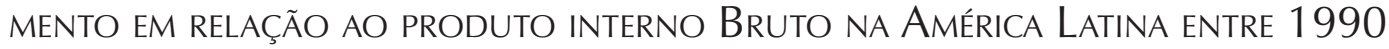
E 2011

Fonte: Red de Indicadores de Ciencia y Tecnología - Iberoamericana e Interamericana (RICYT).

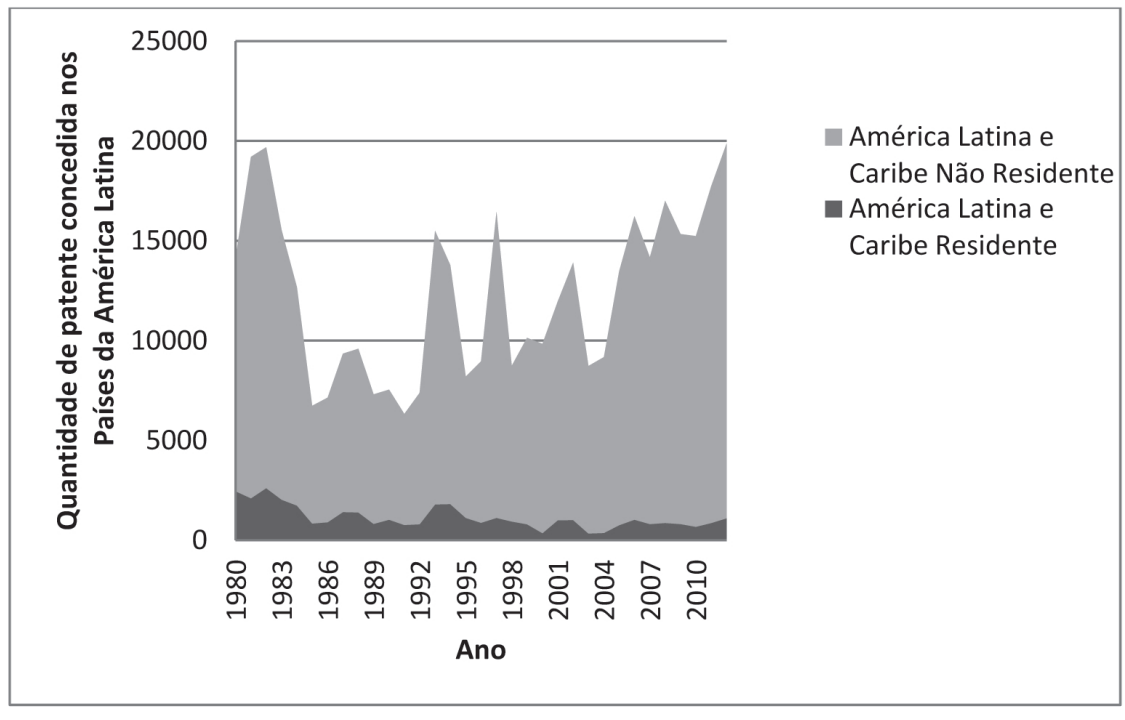

GRÁFICO 02

QuANTIDADE DE PATENTE CONCEDIDA DE NÃO RESIDENTE E RESIDENTE NOS PAÍ́SES DA AMÉRICA LATINA ENTRE 1980 A 2012

Fonte: World Intellectual Property Office. 


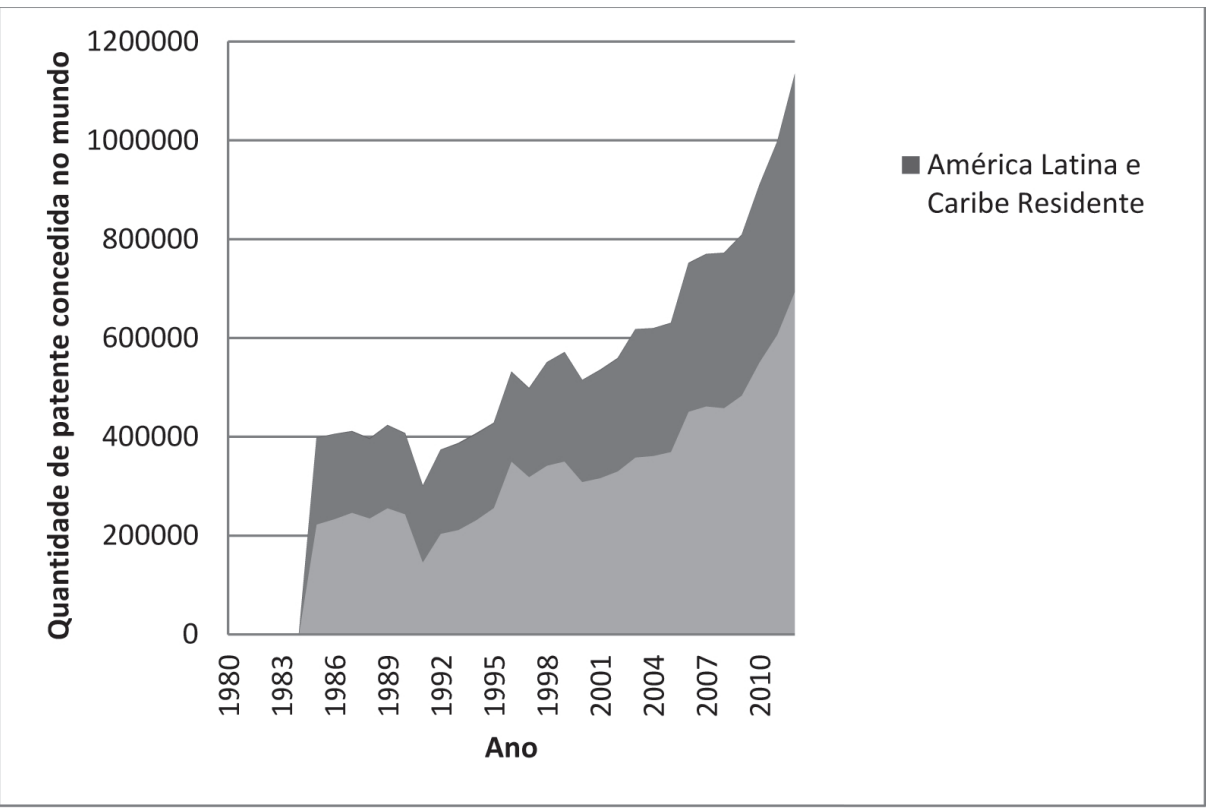

GRÁFICO 03

QuANTIDADE DE PATENTE CONCEDIDA DE NÃO RESIDENTE E RESIDENTE NO MUNDO ENTRE 1985 A 2012

Fonte: World Intellectual Property Office.

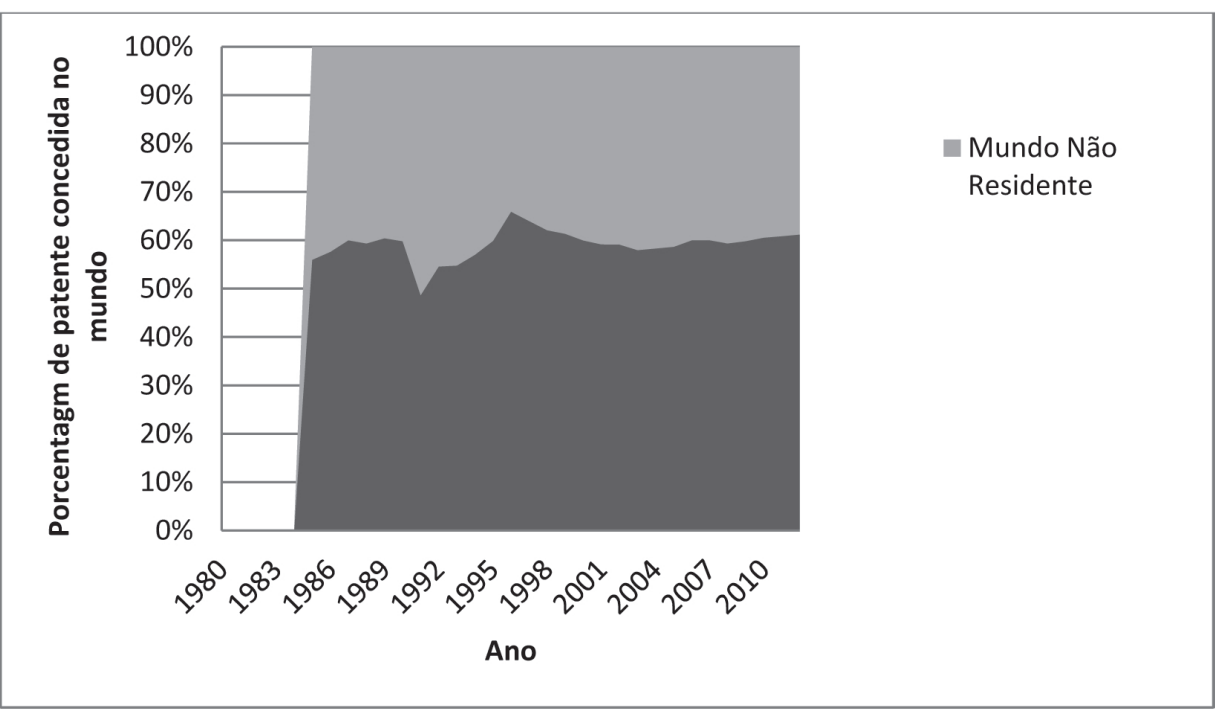

GRÁFICO 04

Percentual de patente concedida de não Residente e Residente NOS PAÍSES DA AMÉRICA LATINA ENTRE 1980 A 2012

Fonte: World Intellectual Property Office. 


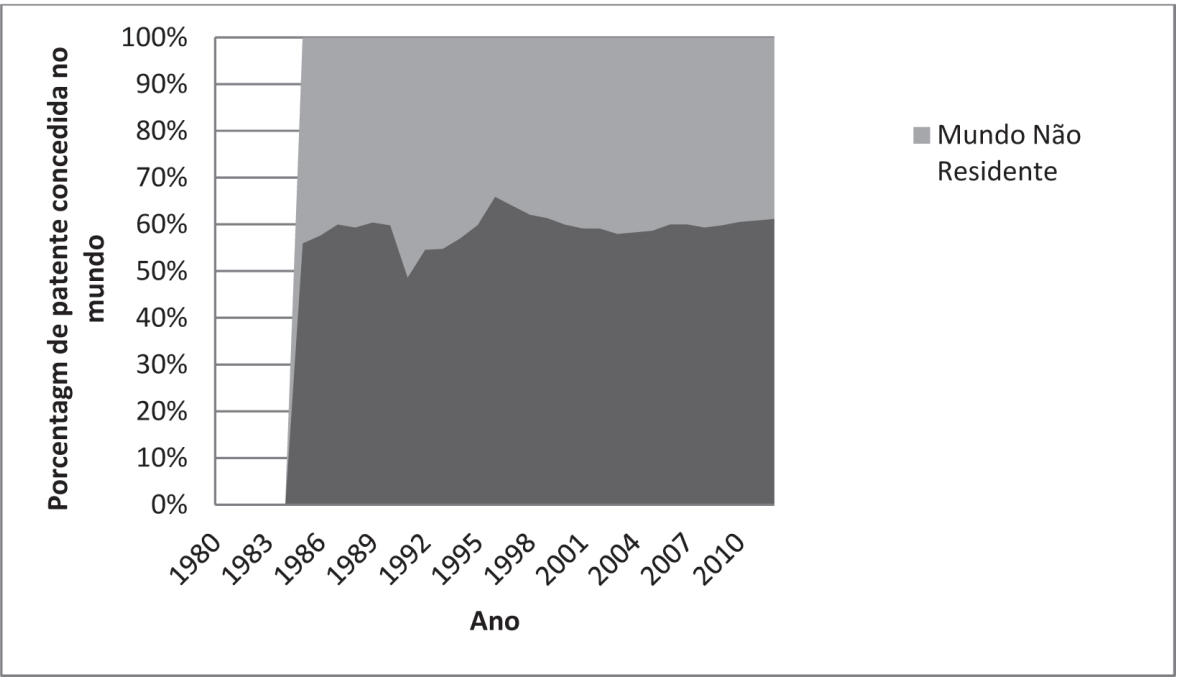

GRÁFICO 05

Percentual de patente concedida de não residente e residente no Mundo ENTRE 1985 A 2012

Fonte: World Intellectual Property Office.

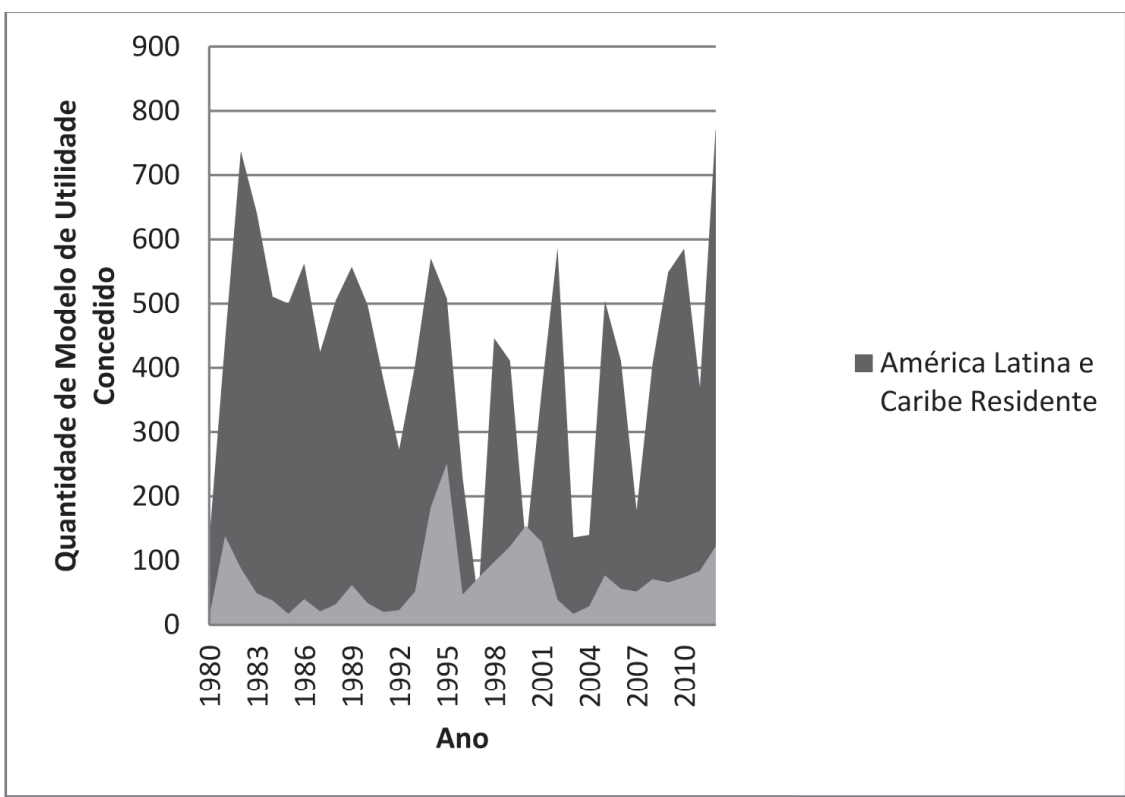

GRÁFICO 06

QuANTIDADE DE MODELO DE UTILIDADE CONCEDIDO DE NÃO RESIDENTE E RESIDENTE NOS PAíses dA AmÉRICA LATINA ENTRE 1980 a 2012 e nO Mundo ENTRE 1985 A 2011 Fonte: World Intellectual Property Office. 


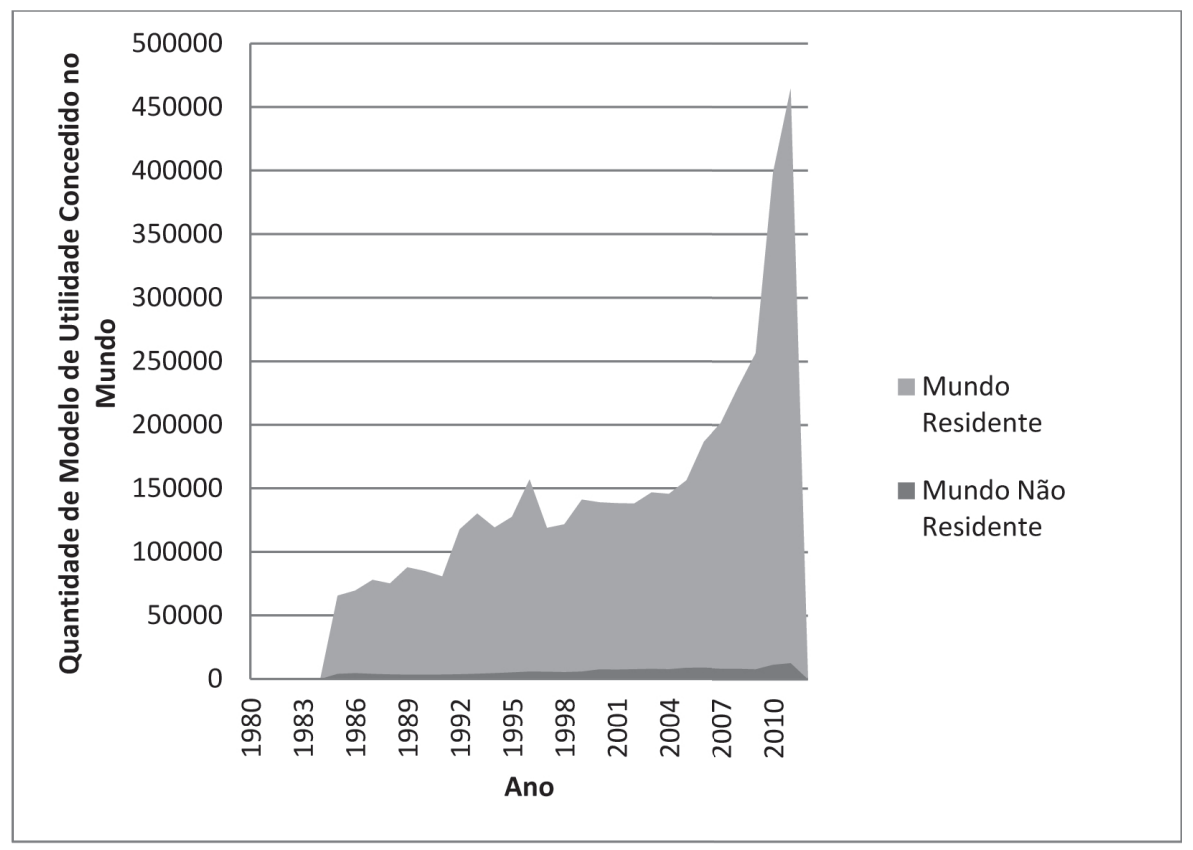

\section{GRÁFICO 07}

QuANTIDADE DE MODELO DE UTILIDADE CONCEDIDO DE NÃO RESIDENTE E RESIDENTE NO Mundo ENTRE 1985 A 2011

Fonte: World Intellectual Property Office.

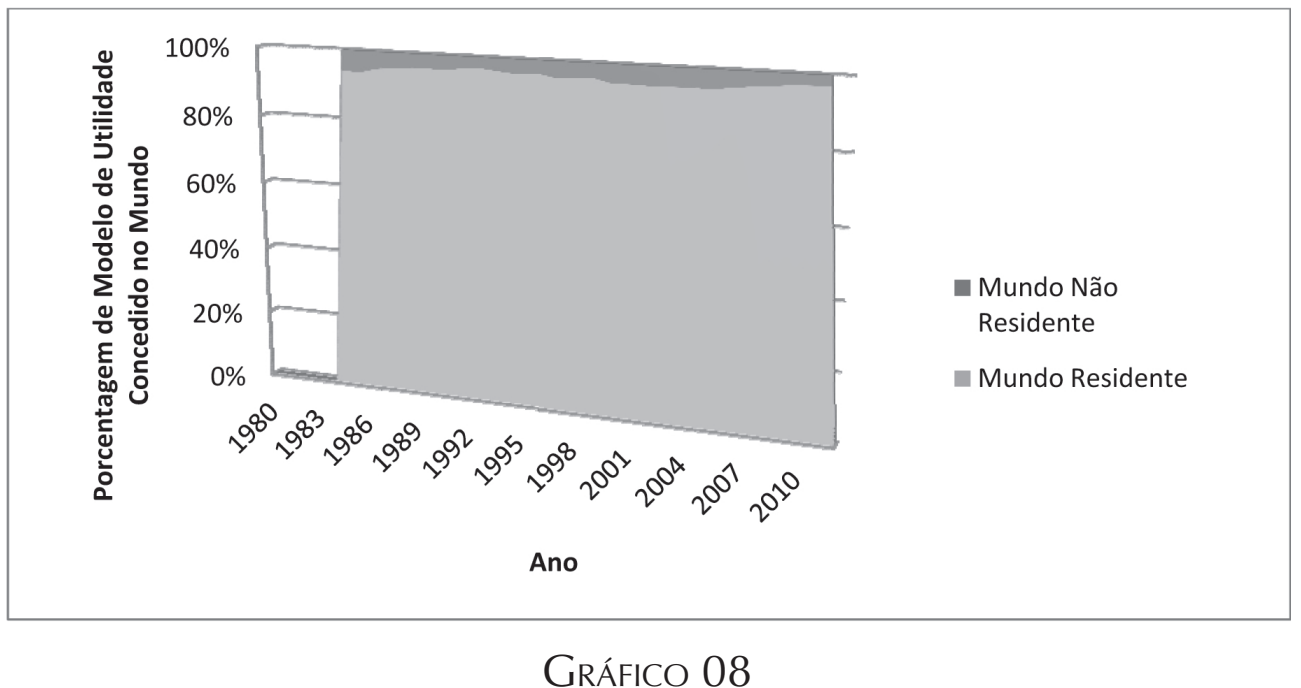

Percentual de modelo de utilidade Concedido de não Residente E RESIDENTE NOS PAíses dA AmÉrICA LATINA ENTRE 1980 a 2012 e nO Mundo ENTRE 1985 A 2011

Fonte: World Intellectual Property Office. 


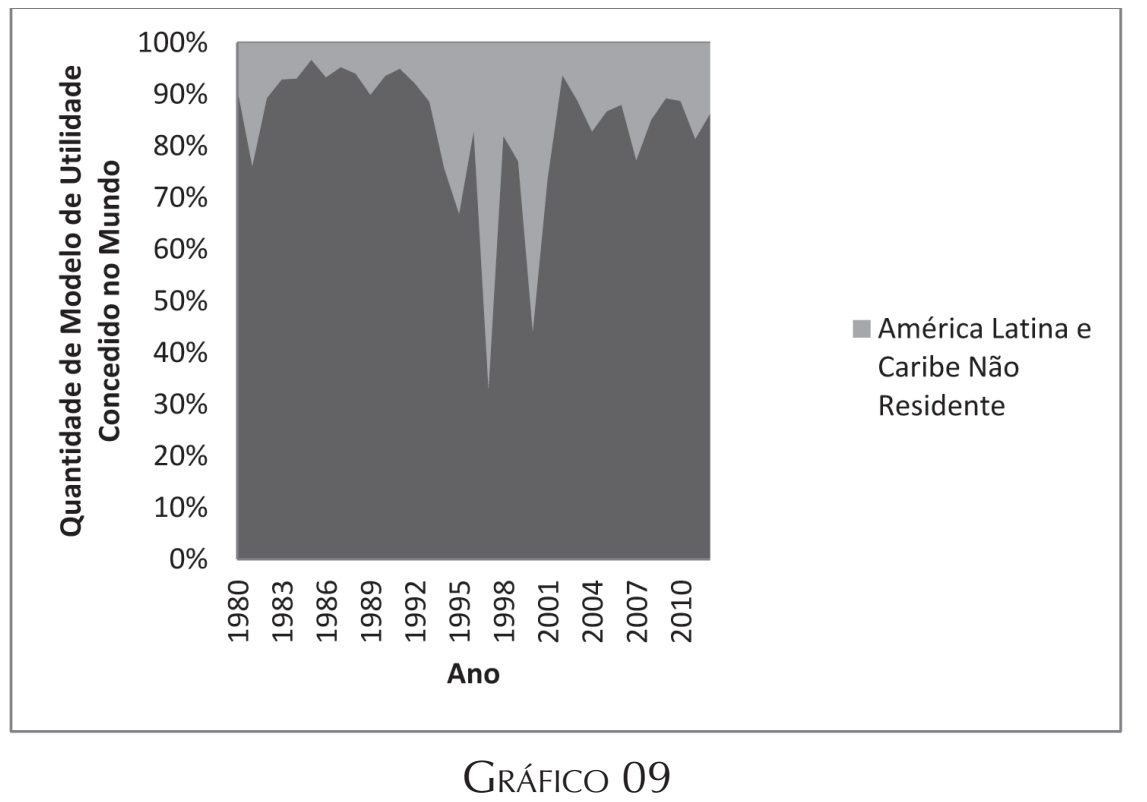

Percentual de modelo de utilidade CONCEDido de não Residente E Residente nOS Países da AmÉriCA Latina entre 1980 a 2012 e nO Mundo ENTRE 1985 A 2011

Fonte: World Intellectual Property Office.

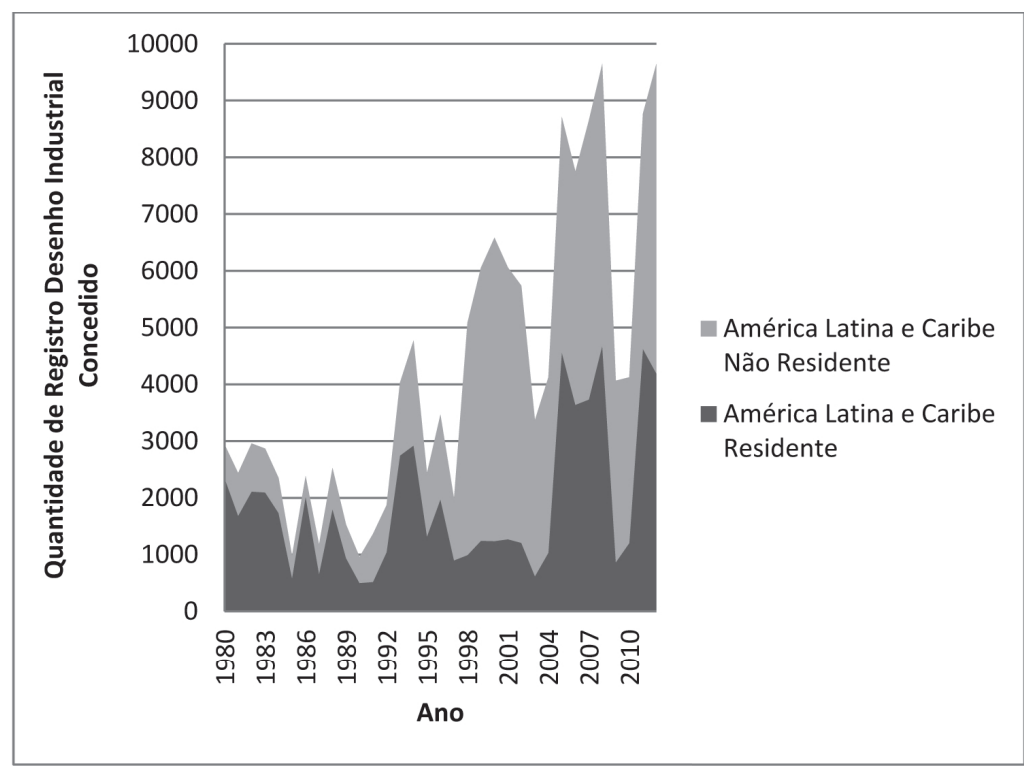

GRÁFICO 10

Quantidade de Registro de Desenho Industrial ReGistrado de não RESIDENTE E RESIDENTE NOS PAÍSES DA AMÉRICA LATINA ENTRE 1980 A 2012 Fonte: World Intellectual Property Offfice. 


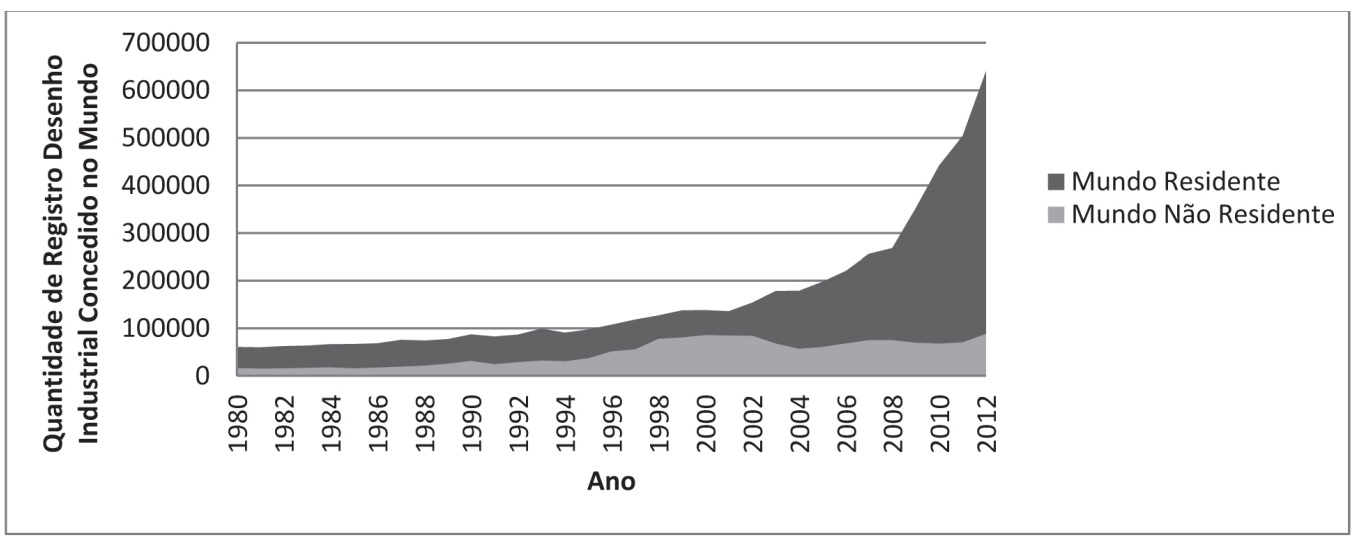

\section{GRÁFICO 11}

Quantidade de Registro de Desenho Industrial reGistrado de não RESIDENTE E RESIDENTE NO MUNDO ENTRE 1980 A 2012

Fonte: World Intellectual Property Offfice.

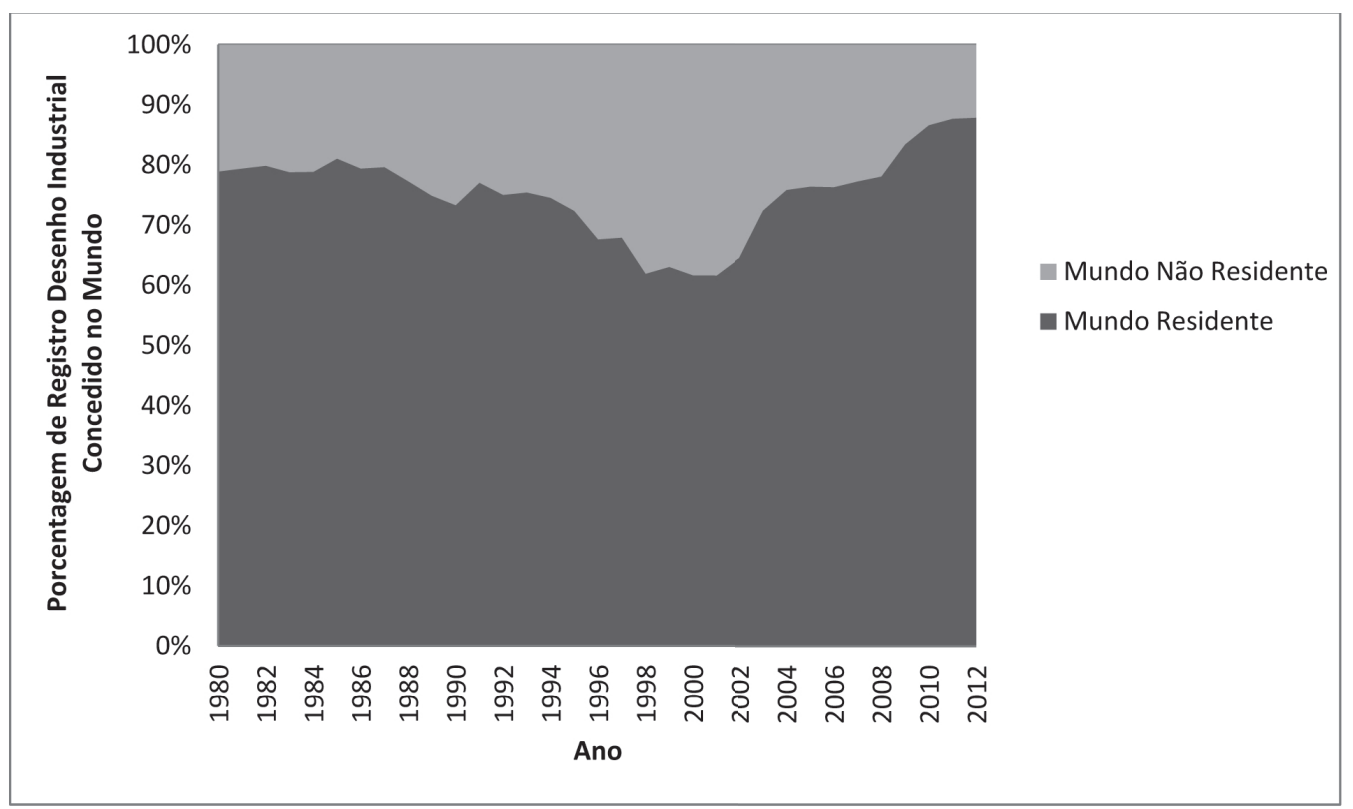

\section{GRÁFICO 12}

Percentual de Registro de Desenho Industrial concedido de não RESIDENTE E RESIDENTE NO MUNDO ENTRE 1980 A 2012

Fonte: World Intellectual Property Office. 


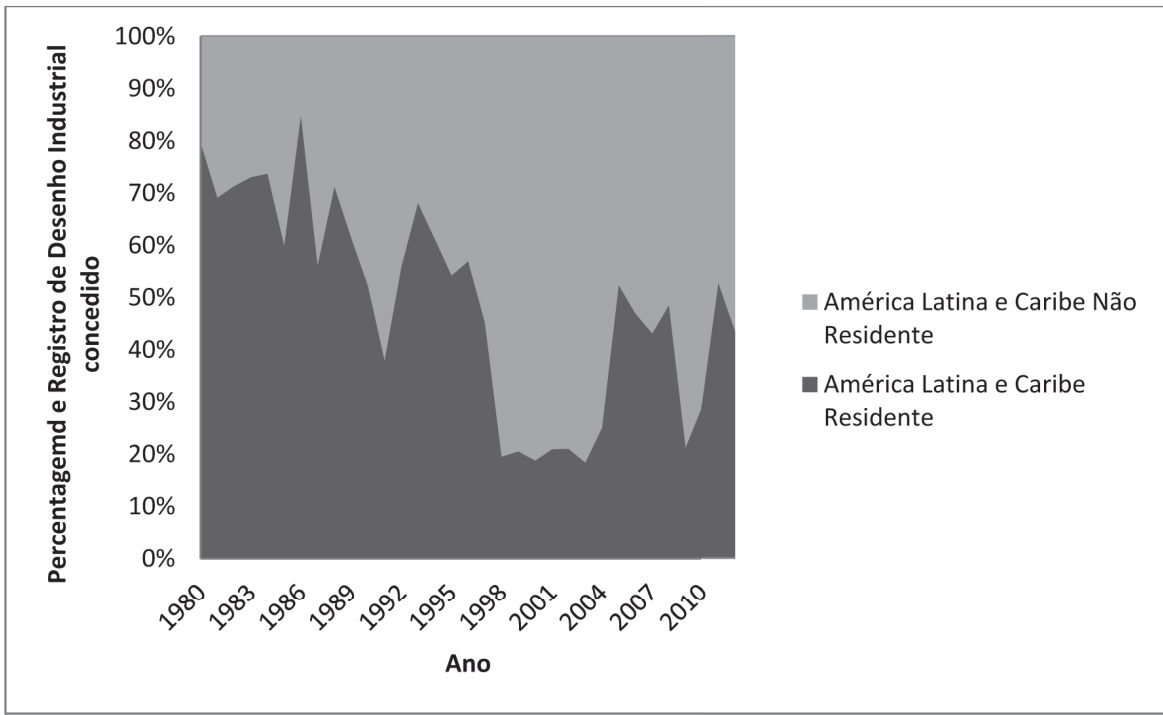

GRÁFICO 13

Percentual de Registro de Desenho Industrial concedido de não RESIDENTE E RESIDENTE NOS PAÍSES DA AMÉRICA LATINA ENTRE 1980 A 2012 Fonte: WIPO.

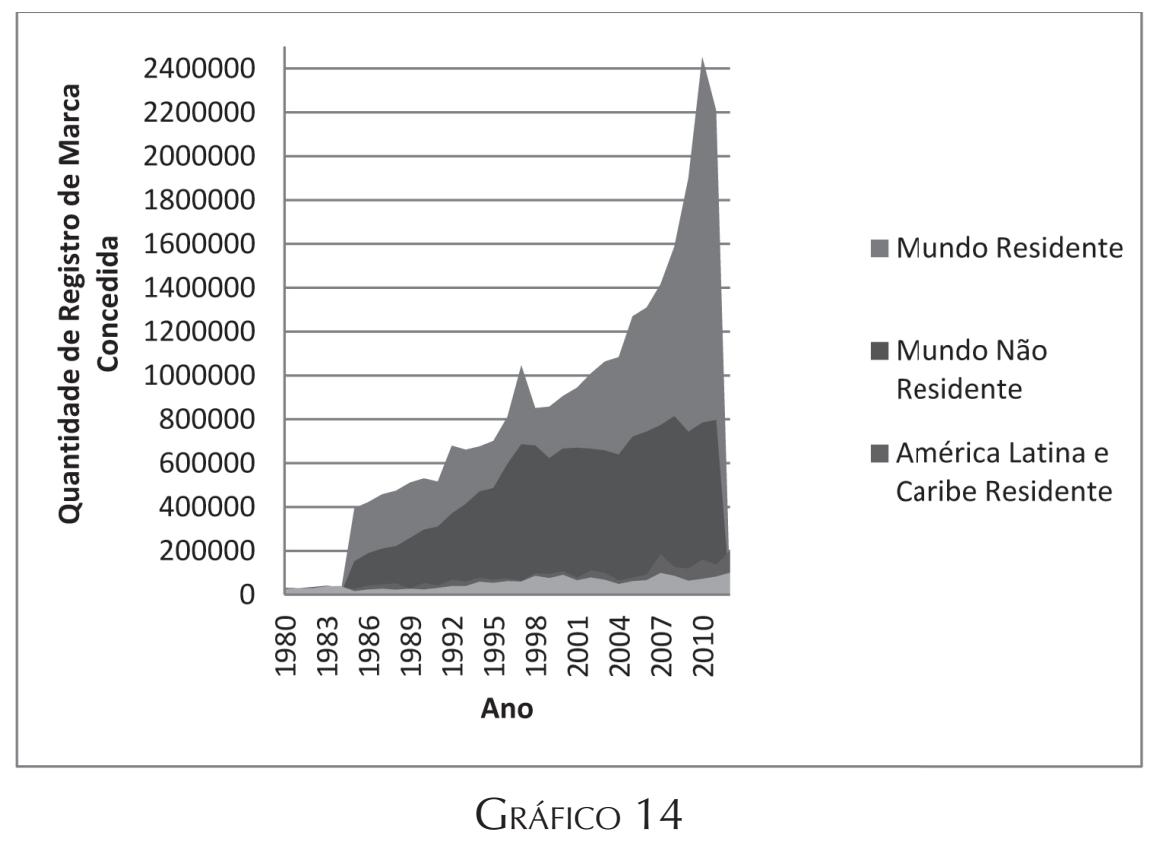

QUANTIDADE DE REGISTRO DE MARCA CONCEDIDO DE NÃO RESIDENTE E RESIDENTE NOS PAÍSES DA AMÉRICA LATINA ENTRE 1980 a 2012 e nO Mundo ENTRE 1985 A 2011 Fonte: World Intellectual Property Office. 


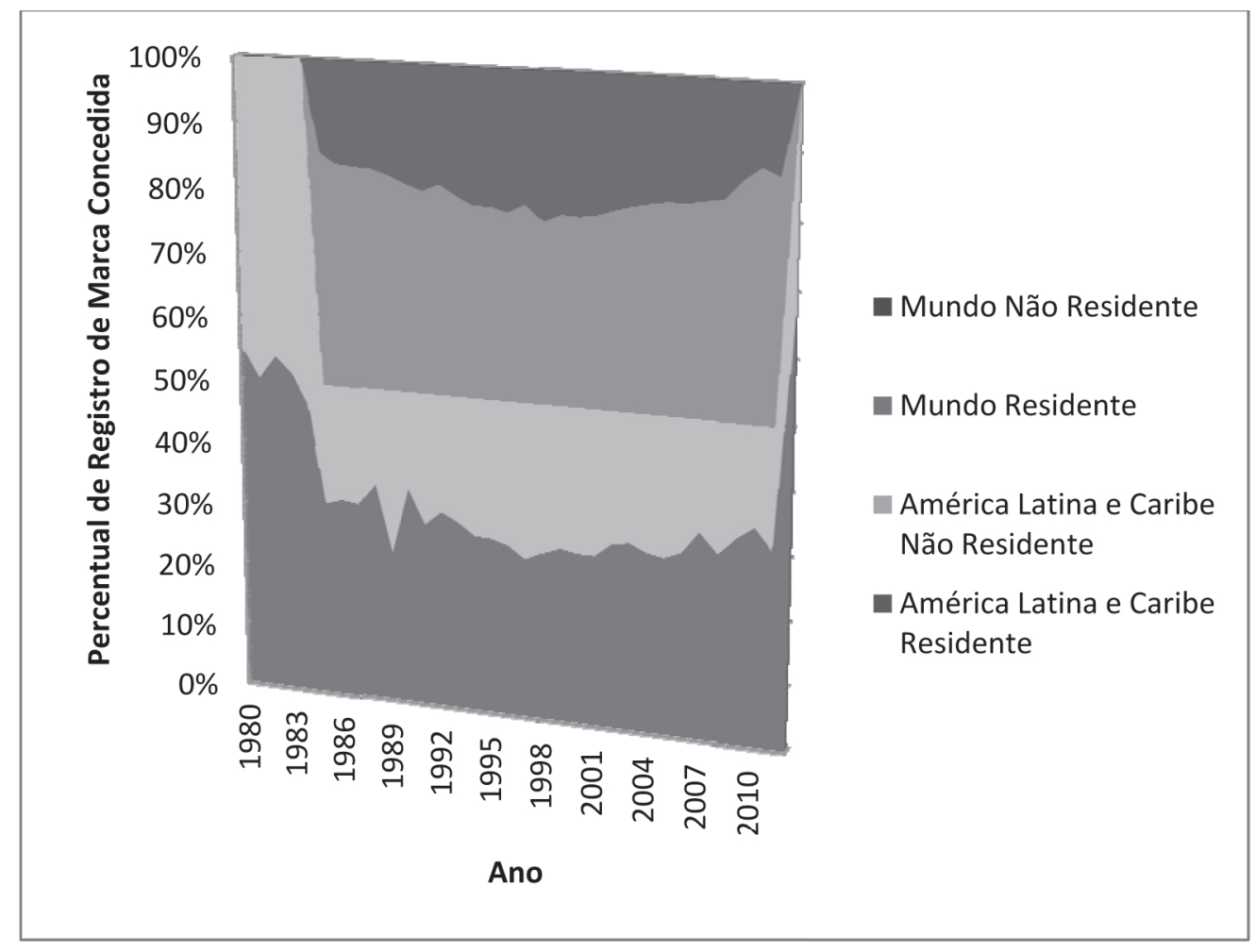

\section{GRÁFICO 15}

Percentual de ReGistro de marCa CONCEDIDO de NÃo RESIDENTE E Residente nOS Países da AmÉriCA Latina entre 1980 a 2012 e nO Mundo ENTRE 1985 A 2011

Fonte: World Intellectual Property Office. 


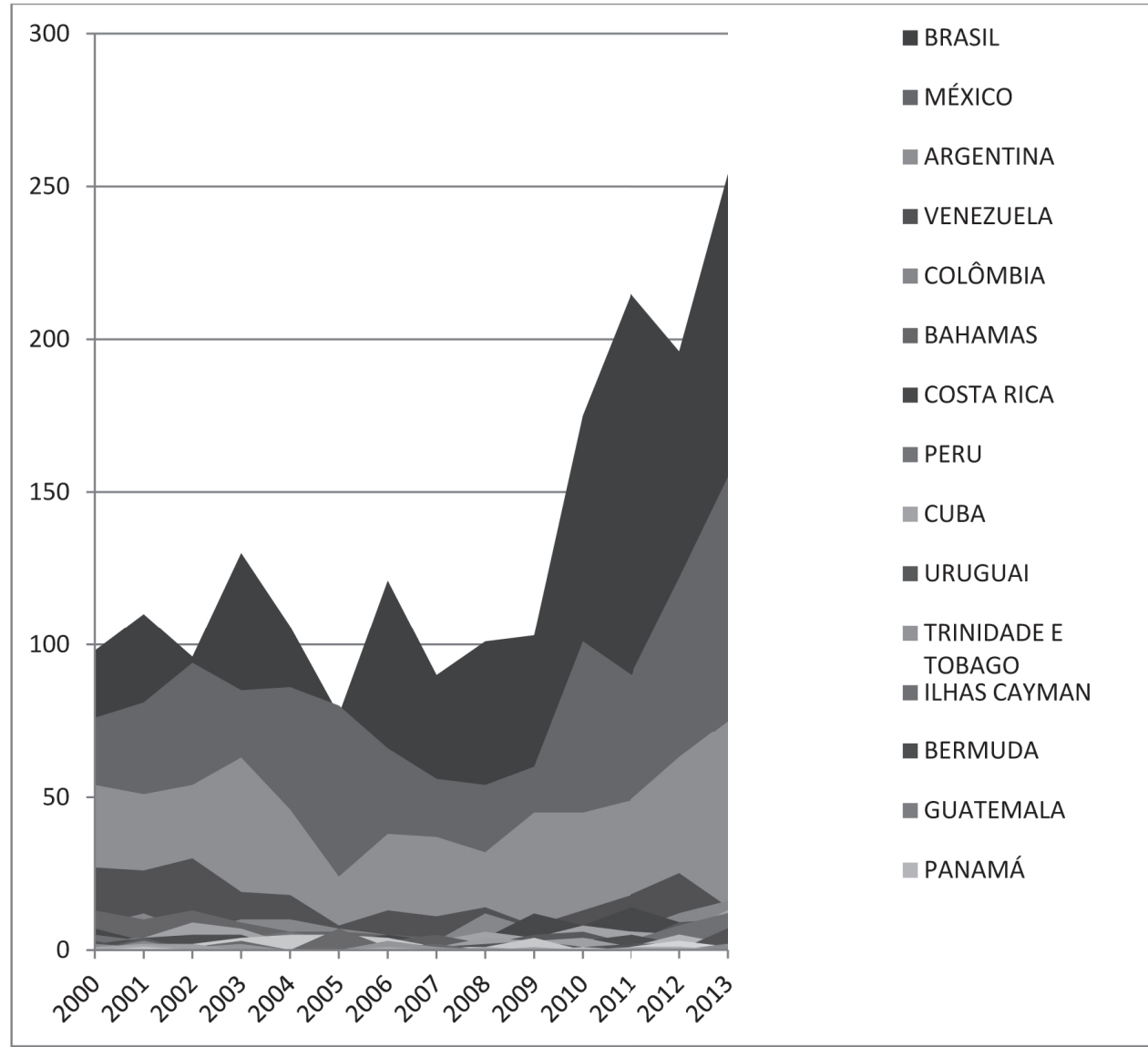

Gráfico 16

Patentes concedidas no United State Patent and Trademark Office ENTRE 2000 e 2013

Fonte: United State Patent and Trademark Office. 